\title{
Chemically Modified Carbon Sensors Mixed or Single for the Determination of Cardiovascular Drug Nafronyl Oxalate in Bulk, Praxilene and Human Fluids
}

\section{Amal F Khorshid*}

Pharmaceutical Analytical Chemistry Department, Faculty of Pharmacy, Nahda University, NUB, Beni-Sueff, Egypt

\begin{abstract}
Three novel chemically modified Carbon Paste Sensors (CMCPs) were proposed for the determination of nafronyl potentiometric in bulk, pharmaceutical dosage form; human plasma/urine. The sensors were based on an ion-pair associates of nafronyl silicotungstic acid (Nf-St) (sensor 1), nafronyl silicomolybdic acid (Nf-SM) (sensor 2), a mixture of (Nf-St)+(Nf-SM) (sensor 3). The modified sensors showed Nernstian slopes ranging from $58.5 \pm 0.5-60.7 \pm 0.5 \mathrm{mV}$ over the concentration ranged from $1.0 \times 10^{-7}-1.0 \times 10^{-2} \mathrm{M}$ and $\mathrm{pH}$ 2.0-6.0 with detection limit $0.1 \mathrm{nM}$. The sensors exhibited good selectivity for nafronyl with respect to inorganic/organic cations, sugars and amino acids. The calibration curve, standard addition and potentiometric titration methods were applied for the determination of nafronyl ion in its bulk powder, pharmaceutical dosage form, and human fluids plasma/urine taken from a healthy volunteer and for the monitoring Praxilene tablets in vitro dissolution rates. Sensor 3 had been the best sensitivity so was successfully used for the determination the solubility products of ion-pair associates. The results were excellent and satisfactory recovery comparable to those obtained with the British Pharmacopoeia.
\end{abstract}

Keywords: Nafronyl oxalate $\mathrm{Nf}-(\mathrm{COOH})_{2}$; Carbon-paste sensor; Potentiometry; Praxilene tablets; in vitro dissolution rates; Solubility product.

\section{Introduction}

Naftidrofuryl oxalate $\left(\mathrm{Nf}-(\mathrm{COOH})_{2}\right)$ is known as nafronyl oxalate, which is an alpha-(1-Naphthylmethyl)-2-tetrahydrofuranpropionic acid diethylaminoethyl ester oxalate. The empirical formula of nafronyl oxalate is $\left(\mathrm{C}_{26} \mathrm{H}_{35} \mathrm{NO}_{7}\right)$ and its molecular weight is (Mol. Wt. 473.56) as shown in Figure 1. Naftidrofuryl oxalate (3200-06-4) belongs to a group of medicines called vasodilator in the treatment of peripheral and cerebral vascular disorders [1,2]. Many sophisticated methods of analytical were showed to determine (Nf), including chromatographic [3-7], spectrophotometric [8], electrochemical method [9-11], phosphorimetric [12-15]. The spectrophotometric methods of drug analysis usually suffer from poor selectivity. Others include a flow injection analysis with fluorescence optosensor [16]. Many of these methods involve derivatization reactions, several time-consuming manipulations, extraction steps, that are liable to various interferences, and are not applicable to colored and turbid solutions either. No methods in the literature for determination [Nf] by Chemical Modified Carbon Paste Sensor (CMCPs).

A Chemically Modified Sensor (CMEs) is one of the electrochemical methods which have been widely used as selective and sensitive analytical methods for the detection of the trace amounts of biologically important compounds. CMEs have important properties of their ability to catalyze the sensor process via significant decreasing of over the potential with respect to unmodified sensor. These sensors are capable<smiles>CCN(CC)CCOC(=O)C(Cc1cccc2ccccc12)CC1CCCO1</smiles>

Figure 1: The chemical structure of Naftidrofuryl oxalate. of considerably enhancing the selectivity in the electroanalytical methods with respect to relatively selective interaction of the electron mediator with the target analyte in a coordination fashion.

The electrochemistry and electroanalysis with carbon pastebased sensors, biosensors, and detectors have been presented and the following two principal conclusions can be made: herein. Firstly: It is the fact that carbon paste still represents one of the most popular sensor materials with almost unlimited applicability in basic research, highly specialized investigations, as well as in practically oriented electroanalysis.

Secondly, the recent turbulences in the area of CPEs, CMCPSs, CPbiosensors, and $\mathrm{CP}$-detectors have shown that carbon paste is also one of the most flexible substrates that obey criteria of the green-chemistry concept; especially, in the area of environmental inorganic analysis. In this respect, a majority of carbon pastes have great promise as a cheap, easy-to-prepare, and in the native form also almost non-toxic material $[17,18]$.

This work describes the construction, potentiometric characterization, and analytical application of a three novel naftidrofuryl-chemically modified carbon paste sensors (Nf-CMCPEs) based on the use of naftidrofuryl silicotungstate (Nf-ST), Naftidrofuryl Silico Molybdate (Nf-SM) and a mixed of (Nf ST+Nf-SM) dissolved in 2-NPPE as pasting liquid. In vitro dissolution testing serves as an important tool for characterizing the biopharmaceutical quality of a product at different stages in its lifecycle. The results presented in the paper show that the sensor constructed for naftidrofuryl ion has a wide concentration range, low limit of detection, good Nernstain slope, and

*Corresponding author: Amal Khorshid F, Pharmaceutical Analytical Chemistry Department, Faculty of Pharmacy, Nahda University, NUB, Beni-Sueff, Egypt, Tel: +2082-2284680; E-mail: amalkorshid@yahoo.com

Received May 24, 2014; Accepted June 13, 2014; Published June 20, 2014

Citation: Khorshid AF (2014) Chemically Modified Carbon Sensors Mixed or Single for the Determination of Cardiovascular Drug Nafronyl Oxalate in Bulk, Praxilene and Human Fluids. J Biosens Bioelectron 5: 153. doi: 10.4172/2155-6210.1000153

Copyright: (C) 2014 Khorshid AF. This is an open-access article distributed under the terms of the Creative Commons Attribution License, which permits unrestricted use, distribution, and reproduction in any medium, provided the original author and source are credited. 
high selectivity over a wide variety of other cations and compared with sensors previously reported [9-11]. In addition, the determination of solubility products of the sparingly soluble naftidrofuryl salts based on CMCPs fabricated in the laboratory and was compared with the solubility products determined by potentiometric/conductimetric method.

\section{Materials and Methods}

\section{Reagents and materials}

All reagents used were chemically pure grade. Doubly distilled water was used throughout all experiments. Naftidrofuryl oxalate and its pharmaceutical preparation (Praxilene tablets, $200 \mathrm{mg} /$ tablet) were provided by MinaPharm-Egypt under license of MERK France. Graphite powder, dibutyl phthalate (DBP), dioctyl phthalate (DOP), tributyl phthalate (TBP), tricresyl phosphate (TCP), 2-nitrophenyl phenyl ether (2-NPPE), silicotungestic acid (STA), silicomolybdic acid (SMA) were selective products from Aldrich.

Chloride solution with $0.5 \mathrm{M}$ of each of the following cations: $\mathrm{K}^{+}, \mathrm{Na}^{+}, \mathrm{NH}_{4}^{+}, \mathrm{Ni}^{2+}, \mathrm{Co}^{2+}, \mathrm{Cu}^{2+}, \mathrm{Zn}^{2+}, \mathrm{Ba}^{2+}, \mathrm{Mn}^{2+}, \mathrm{Cr}^{3+}, \mathrm{Mg}^{2+}$, and $\mathrm{Fe}^{3+}$ solutions were obtained from Merck. Glucose anhydrous, lactose monohydrate, maltose, urea, ascorbic acid, aspirin, L-threonine, L-lysine, L-cystine, and L-glycine were obtained from Aldrich. Plasma was used within $24 \mathrm{~h}$ and provided by VACSERA (Giza, Egypt) while urine samples were obtained from healthy volunteers. Corn oil, sodium hydroxide and hydrochloric acid are from chemical stores, (GizaEgypt).

\section{Apparatus}

The Electrochemical system: The potentiometric measurements were carried out at $25 \pm 1^{\circ} \mathrm{C}$ with a Jenway 3515 digital $\mathrm{pH} / \mathrm{mV}$ meter with a WTW-packed saturated calomel sensor (SCE) was used as an external reference sensor. The electrochemical system was as follows: CMCPS/test solution//SCE. The dissolution was studied using USP XXXII [19] method with apparatus II [20], which was provided in vitro dissolution testing for controlled/modified-release preparations, and more uniform flow profile. The apparatus used for this purpose is model "SR8Plus", CA USA Hanson Research; with number "73-100$116 "$ and the spectrophotometer double beam instrumentUV-1800 Shimadzu (Japan).

Preparation of ion-pair: The ion-exchangers, naftidrofuryl silicotungstate (Nf-ST), naftidrofuryl silicomolybdate (Nf-SM) were prepared by addition of $50 \mathrm{ml}$ of $1.0 \times 10^{-2} \mathrm{M}$ naftidrofuryl oxalate Nf$(\mathrm{COOH})_{2}$ solution to $50 \mathrm{ml}$ of $2.5 \times 10^{-3} \mathrm{M}$ STA and SMA. The resulting precipitates were left in contact with their mother liquor overnight to assure complete coagulation. The precipitates were washed thoroughly with distilled water, then filtered and dried at room temperature and ground to fine powder. The resulting precipitates were left in contact with their mother liquor overnight to assure complete coagulation. The formation and purity of the ion-pairs and ion-associates, chemical compositions of the precipitates were checked by elemental analysis for carbon, hydrogen and nitrogen at the Micro Analytical Center, Faculty of Science, Cairo University.

Preparation of carbon paste sensors: Chemically modified carbon paste sensors (CMCPS-Nf) were prepared as previously described [21]. The sensor was used directly for potentiometric measurements without preconditioning requirements. A fresh surface of the paste was obtained by squeezing more out. The surplus paste was wiped out and the freshly exposed surface was polished on a paper until the surface showed shiny appearance.

Effect of $\mathbf{p H}$ on the sensor potential: The effect of $\mathrm{pH}$ of the test solution in batch measurements, on the potential values of the sensor system in solutions of different concentrations $\left(1.0 \times 10^{-3}, 1.0 \times 10^{-4}\right.$ and $\left.1.0 \times 10^{-5} \mathrm{M}\right)$ of the $\mathrm{Nf}-(\mathrm{COOH})_{2}$ was studied. Aliquots of the drug solution $(50 \mathrm{ml})$ were transferred to $100 \mathrm{ml}$ titration cell and the tested ion-selective sensor in conjunction with the calomel reference sensor, and a combined glass sensor were immersed in the same solution. The $\mathrm{mV}$ and $\mathrm{pH}$ readings were simultaneously recorded. The $\mathrm{pH}$ of the solution was varied over the range of 1.0-10.0 by addition of very small volumes of $2 \mathrm{M} \mathrm{HCl}$ and/or (0.1-1.0 M) NaOH solution. The $\mathrm{mV}$-readings were plotted against the $\mathrm{pH}$-values for the different concentrations.

Temperature effect on the sensor: The study of thermal stability of the sensors, calibration graphs were constructed at different test solution-temperatures covering the range $25-50^{\circ} \mathrm{C}$. The slope, the standard sensor potentials $\left(\mathrm{E}^{\circ}\right)$, usable concentration ranges, and response time of the sensors corresponding to each temperature were reported.

Sensors selectivity: The matched potential method is unique in that it depends neither on the Nicolsky-Eisenman equation nor on any of its modifications. This method was recommended in 1995 by IUPAC as a method that gives analytically relevant practical selectivity coefficient values. To determine the selectivity coefficients of different interfering ions for the studied sensors, a reference solution $\left(a_{A}\right)$ is added an amount of the drug to give a final concentration of $\left(\mathrm{a}_{\mathrm{A}}^{-}\right)$, the shift in potential change $(\Delta \mathrm{E})$ is thus measured. To a reference solution containing the same concentration $\left(\mathrm{a}_{\mathrm{A}}\right)$, a certain amount of interference ion that cause the same $(\Delta \mathrm{E})$ value is thus determined $\left(A_{\mathrm{i}}\right)$. The following equation is used to calculate the selectivity values of $\log \mathrm{K}_{\mathrm{Nf, \textrm {J } ^ { \mathrm { z } }}}^{\mathrm{pot}}[22,23]$

$$
K_{N f . J^{Z+}}^{P O T}=\frac{\left.\left(a_{A}{ }^{-}-a_{d r u g}\right)\right)}{a_{j}}
$$

Where: $a_{A}{ }^{-}$is the initial concentration of drug, $\mathrm{a}_{\mathrm{drug}}$ is the activity of the added drug and $a_{j}$ is the activity of the added interfering ion producing the same increase in potential.

In addition, the separate solutions method (SSM) was used. Two values of potential were determined for the same drug concentration and the interferents. The selectivity values of $\log \mathrm{K}_{\mathrm{Nf}, \mathrm{J}^{z^{+}}}^{\mathrm{pot}}$ are calculated using the following equation [24]

$$
\log \mathrm{K}_{\mathrm{Nf}, \mathrm{J}^{\mathrm{z}^{+}}}^{\mathrm{pot}}=\frac{\mathrm{E}_{2}-\mathrm{E}_{1}}{\mathrm{~S}}+\log [\mathrm{Drug}]-\log \left[\mathrm{J}^{\mathrm{z}+}\right]^{1 / \mathrm{z}}
$$

Where: $\mathrm{E}_{1}$ and $\mathrm{E}_{2}$ are the sensor potentials of $10^{-3} \mathrm{M}$ solution of each of the $\mathrm{Nf}$ drug and interfering cation, $\mathrm{J}^{\mathrm{z}}$, respectively and $\mathrm{S}$ is the slope of the calibration graph.

\section{Determination by Standard addition method}

In bulk powder: The potentiometric determination by the standard additions method was applied, in which a known incremental change is made through the addition of standard solution of the sample. This was achieved by adding known volumes of standard $\mathrm{Nf}-(\mathrm{COOH}){ }_{2}$ drug solution to $50 \mathrm{ml}$ water containing different amounts of the investigated drug in its pure state. The change in $\mathrm{mV}$ reading was recorded for each increment and used to calculate the concentration of the drug in sample solution using the following equation [24]: 


$$
C_{X}=C_{S}\left(\frac{V_{s}}{V_{X}+V_{S}}\right)\left(10^{\mathrm{n}(\Delta \mathrm{E} / \mathrm{S})}-\frac{V_{X}}{V_{S}+V_{X}}\right)^{-1}
$$

Where $C_{x}$ is the concentration to be determined, $V_{x}$ is the volume of the original sample solution, $\mathrm{V}_{\mathrm{s}}$ and $\mathrm{C}_{\mathrm{s}}$ are the volume and concentration of the standard solution added to the sample to be analyzed, respectively, $\Delta \mathrm{E}$ is the change in potential after addition of certain volume of standard solution, and $\mathrm{S}$ is the slope of the calibration graph.

In dosage form: For analysis of tablets of drug, the contents of five coated (Praxilene tablets, $200 \mathrm{mg} /$ tablet) were powdered and an accurately weighed (200-250 mg) portion from each was mixed with $50 \mathrm{ml}$ doubly distilled water, shaken in a mechanical shaker for about $30 \mathrm{~min}$ and filtered into a $100 \mathrm{ml}$ volumetric flask, the solution was completed to the mark with doubly distilled water and shaken. Different volumes of the solution $(1.0-10 \mathrm{ml})$ were taken and subjected to the standard additions technique of the potentiometric determination.

In human fluids: In spiked human plasma three of centrifugation $20 \mathrm{ml}$ stoppered shaking tubes containing $0.5 \mathrm{ml} \mathrm{Nf}-(\mathrm{COOH})_{2}$ drug solution from the concentration $1 \times 10^{-3}, 1 \times 10^{-4}$ and $1 \times 10^{-5} \mathrm{M}$ and spiked with $4.5 \mathrm{ml}$ plasma separately to each tube. An acetate buffer $\mathrm{pH} 4$ was added to the plasma until adjusted the $\mathrm{pH}$. The modified sensor was immersed in conjunction with the calomel electrode in these solutions and then washed with water between measurements. The emf produced for each solution was measured by the proposed sensor, and the concentration of $\mathrm{Nf}-(\mathrm{COOH})_{2}$ drug was determined from the corresponding sensor calibration and standard addition methods.

In spiked urine five $\mathrm{ml}$ urine were putted to a $100 \mathrm{ml}$ volumetric flask and spiked with different quantities of the concentrations from $1.0 \times 10^{-6}$ to $5.0 \times 10^{-4} \mathrm{M}$ drug $\mathrm{Nf}-(\mathrm{COOH})_{2}$ drug then left stirred for 5 min, completed to the mark with doubly bidistilled water. A small volume of $0.01 \mathrm{M} \mathrm{HCl}(0.1-2.0 \mathrm{ml})$ was added to adjust the $\mathrm{pH}$ ranging from 4 to 5 . This spiked urine was subjected to the standard addition method for drug determination.

\section{Determination by potentiometric titrations}

An aliquot of the Nf- $(\mathrm{COOH})_{2}$ drug containing different weights ranging from $4.73-47.36 \mathrm{mg}$ was dissolved into $50 \mathrm{ml}$ by bidistilled water, the resulting solutions were titrated against $0.0025 \mathrm{M}$ SMA and $0.0025 \mathrm{M}$ STA using the corresponding sensor(s). The end points were determined from the conventional S-shaped curves by the first and second derivative plots. The same procedure was applied for the tablets.

Content uniformity assay of Praxilene tablets: A tablet of Praxilene, (200 mg/tablet) was immersed in the measuring flask for measuring each sensor was immediately putted in the sample solution three times and then washed between each individual measurement with distilled water to reach steady potential. The content uniformity was evaluated from the calibration graph by using the mean potential. For the spectrophotometric measurements by employing UV absorbance $\lambda \max 283 \mathrm{~nm}$ with the standard solution.

Determination of the solubility product constant: About $0.5 \mathrm{~g}$ portion of each ion-associate $\mathrm{Nf}_{4}-\mathrm{ST}$ and $\mathrm{Nf}_{4}$-SM was added to $50 \mathrm{ml}$ distilled water. The solution were shaken for about $24 \mathrm{~h}$ and left to stand for a week to attain a stable equilibrium. Then, each saturated solution was decanted to a dry beaker and the equilibrium concentration of drug ion present was determined potentiometriclly using the corresponding sensors by the standard additions method, and hence the solubilities and the solubility product constants of the ion associates were calculated. The conductivity of these solutions were measured at $25^{\circ} \mathrm{C}$ and the specific conductivities $\left(\lambda_{\mathrm{o}}\right)$, corrected for the effect of solvent, were calculated and used to obtain the equivalent conductivities $(\lambda)$ of these solutions. Straight line plots of $\lambda$ versus $\sqrt{ } \mathrm{c}$ were constructed and $\lambda_{0 \mathrm{Nf}-(\mathrm{COOH})_{2}}, \lambda_{0 \mathrm{STA}}$ and ${ }_{0 \text { SMA }}$ were determined from the intercept of the respective line with the $\lambda$-axis. The activity coefficients of the ions employed were taken as unity because all the solutions were sufficiently

dilute. The values of $\lambda_{0}$ (Nf-ST) and $\lambda_{0}$ (Nf-SM) were calculated using Kohlrausch's law of independent migration of ions [25].

The solubility $(\mathrm{S})$ and solubility product $\left(\mathrm{K}_{\mathrm{sp}}\right)$ of a particular ion associate were calculated using the following equations:

$$
\begin{aligned}
& \mathrm{S}=\mathrm{K}_{\mathrm{s}} \mathrm{x} 1000 \lambda_{0 \text { (ion-associate) }} \\
& \mathrm{K}_{\mathrm{sp}}=256 \mathrm{~S}^{5} \text { for } 1: 4 \text { ion-associates }
\end{aligned}
$$

Where $\mathrm{K}_{\mathrm{s}}$ is the specific conductivity of a saturated solution of the ion associate, determined at $25^{\circ} \mathrm{C}$ and corrected for the effect of solvent. The saturated solution was made by stirring a suspension of the solid precipitate in distilled water for $60 \mathrm{~min}$ and then leaving it for $24 \mathrm{~h}$ at $25^{\circ} \mathrm{C}$ before measuring the conductivities.

Dissolution: One tablet of Praxilene, $(200 \mathrm{mg} / \mathrm{tablet})$ was placed in one vessel of tablet dissolution instruments apparatus 2 (paddle method). In vitro release study, the testing liquids, prepared from gastric media permit the dissolution medium $\mathrm{pH} 1.2(900 \mathrm{ml}$ of $0.01 \mathrm{M}$ $\mathrm{HCl})$ was maintained at $37 \pm 0.5^{\circ} \mathrm{C}$ for $2 \mathrm{~h}$. The dissolution speed of the naftidrofuryl tablet is measured with gentle agitation $(60 \mathrm{rpm})$, to come close to physiological conditions (coated tablet). At intervals time, the investigated sensor in conjunction with (SCE) reference sensor recorded the potential values and the amount of releasing was calculated from the calibration graph.

For the spectrophotometric measurements, $5.0 \mathrm{ml}$ aliquots of the dissolution solution were withdrawn, filtered, diluted with $0.01 \mathrm{M} \mathrm{HCl}$ and the concentration of samples was analyzed using UV spectrophotometer (1800, Shimadzu, Japan) and the absorbencies were measured at $\lambda \max 283 \mathrm{~nm}$. A calibration graph was used for drug release calculation.

\section{Result and Discussion}

\section{The nature of binder and the effect of composition}

It is well known that, the sensitivity and linearity for a given CMCPs depend significantly on the nature with the amount of the modifier in the paste and the ratios of ion-exchanger(s)/graphite/binder that significantly influence the sensitivity and selectivity of sensors. For this reason, the influence of the binder type and its quantity on the characteristics of the studied sensors was investigated by using five binder with different polarities including TCP, DOP, DBP, TBP and 2-NPPE as shown in Table 1. In addition, five pastes of varying nature and ratios of ion-exchanger(s)/graphite/binder were prepared for the systematic investigation of each paste composition as shown in the same table. As can be seen from the emf-pDs plots Figure 2 the sensor with 2-NPPE as a solvent mediator produced the Nernstian response, likely due to better dielectric characteristics of 2-NPPE comparing to other solvents, and the ability of 2-NPPE to extract naftidrofuryl ions from the aqueous solution to the organic paste phase. Trials are done to improve the performance characteristics of the sensors, as the presence of a mixture. When mixed different percentages of Nf-SM ion-exchanger, to Nf-ST, it is found that, mixed $(2.5 \% \mathrm{Nf}-$ 
Citation: Khorshid AF (2014) Chemically Modified Carbon Sensors Mixed or Single for the Determination of Cardiovascular Drug Nafronyl Oxalate in Bulk, Praxilene and Human Fluids. J Biosens Bioelectron 5: 153. doi: 10.4172/2155-6210.1000153

Page 4 of 10

\begin{tabular}{|c|c|c|c|c|c|c|}
\hline \multicolumn{3}{|c|}{ Composition\% (w/w) } & \multirow{2}{*}{ Slope (mV/decade) } & \multirow{2}{*}{ C.R. (M) } & \multirow{2}{*}{ LOD (M) } & \multirow{2}{*}{$R(s)$} \\
\hline Binder & Graphite & Nf-ST & & & & \\
\hline & & TCP & & & & \\
\hline 0.5 & 55.0 & 44.5 & $-55.5 \pm 1.5$ & $1.00 \times 10^{-6}-5.00 \times 10^{-3}$ & $7.90 \times 10^{-7}$ & $\leq 7$ \\
\hline 1.0 & 55.0 & 44.0 & $-56.7 \pm 1.0$ & $7.90 \times 10^{-7}-1.00 \times 10^{-3}$ & $5.00 \times 10^{-7}$ & $\leq 7$ \\
\hline 3.0 & 55.0 & 42.0 & $-58.0 \pm 0.5$ & $2.50 \times 10^{-7}-1.00 \times 10^{-3}$ & $1.00 \times 10^{-7}$ & $\leq 5$ \\
\hline \multirow[t]{2}{*}{5.0} & 55.0 & 40.0 & $-56.8 \pm 0.5$ & $5.00 \times 10^{-7}-1.00 \times 10^{-3}$ & $1.25 \times 10-7$ & $\leq 6$ \\
\hline & & DOP & & & & \\
\hline 0.5 & 55.0 & 44.5 & $-53.5 \pm 1.5$ & $1.00 \times 10^{-6}-9.70 \times 10^{-3}$ & $7.64 \times 10^{-7}$ & $\leq 9$ \\
\hline 1.0 & 55.0 & 44.0 & $-54.7 \pm 1.0$ & $5.00 \times 10^{-7}-7.66 \times 10^{-3}$ & $2.50 \times 10^{-7}$ & $\leq 9$ \\
\hline 3.0 & 55.0 & 42.0 & $-55.0 \pm 1.5$ & $1.50 \times 10^{-7}-5.00 \times 10^{-3}$ & $1.00 \times 10^{-7}$ & $\leq 8$ \\
\hline \multirow[t]{2}{*}{5.0} & 55.0 & 40.0 & $-54.8 \pm 0.5$ & $5.50 \times 10^{-7}-7.94 \times 10^{-3}$ & $2.50 \times 10-7$ & $\leq 9$ \\
\hline & & DBP & & & & \\
\hline 0.5 & 55.0 & 44.5 & $-54.5 \pm 1.5$ & $2.50 \times 10^{-6}-6.40 \times 10^{-3}$ & $1.50 \times 10^{-6}$ & $\leq 10$ \\
\hline 1.0 & 55.0 & 44.0 & $-54.5 \pm 1.0$ & $5.00 \times 10^{-6}-5.00 \times 10^{-3}$ & $2.00 \times 10^{-6}$ & $\leq 12$ \\
\hline 3.0 & 55.0 & 42.0 & $-55.0 \pm 1.5$ & $1.99 \times 10^{-6}-1.00 \times 10^{-3}$ & $7.50 \times 10^{-7}$ & $\leq 10$ \\
\hline \multirow[t]{2}{*}{5.0} & 55.0 & 40.0 & $-53.5 \pm 0.5$ & $5.80 \times 10^{-6}-6.31 \times 10^{-3}$ & $2.50 \times 10^{-6}$ & $\leq 10$ \\
\hline & & TBP & & & & \\
\hline 0.5 & 55.0 & 44.5 & $-53.5 \pm 1.5$ & $1.00 \times 10^{-6}-1.00 \times 10^{-3}$ & $1.50 \times 10^{-6}$ & $\leq 10$ \\
\hline 1.0 & 55.0 & 44.0 & $-54.7 \pm 1.0$ & $5.00 \times 10^{-7}-1.66 \times 10^{-3}$ & $2.00 \times 10^{-6}$ & $\leq 12$ \\
\hline 3.0 & 55.0 & 42.0 & $-55.0 \pm 1.5$ & $1.00 \times 10^{-6}-1.00 \times 10^{-3}$ & $5.50 \times 10^{-7}$ & $\leq 10$ \\
\hline \multirow[t]{2}{*}{5.0} & 55.0 & 40.0 & $-52.8 \pm 0.5$ & $5.00 \times 10^{-6}-6.50 \times 10^{-3}$ & $2.50 \times 10^{-6}$ & $\leq 10$ \\
\hline & & 2-NPPE & & & & \\
\hline 0.5 & 55.0 & 44.5 & $-56.5 \pm 1.5$ & $3.99 \times 10^{-8}-5.00 \times 10^{-3}$ & $2.52 \times 10^{-8}$ & $\leq 7$ \\
\hline 1.0 & 55.0 & 44.0 & $-57.5 \pm 1.0$ & $3.50 \times 10^{-8}-7.94 \times 10^{-3}$ & $2.00 \times 10^{-8}$ & $\leq 7$ \\
\hline 3.0 & 55.0 & 42.0 & $-59.0 \pm 0.5^{*}$ & $2.50 \times 10^{-8}-2.50 \times 10^{-3}$ & $1.25 \times 10^{-8}$ & $\leq 5$ \\
\hline 5.0 & 55.0 & 40.0 & $-57.8 \pm 0.5$ & $5.50 \times 10^{-8}-6.31 \times 10^{-3}$ & $4.12 \times 10^{-8}$ & $\leq 6$ \\
\hline Nf-SM & & 2-NPPE & & & & \\
\hline 0.5 & 55.0 & 44.5 & $-54.5 \pm 1.5$ & $8.99 \times 10^{-8}-5.00 \times 10^{-3}$ & $7.90 \times 10^{-8}$ & $\leq 7$ \\
\hline 1.0 & 55.0 & 44.0 & $-56.5 \pm 1.0$ & $7.25 \times 10^{-8}-7.94 \times 10^{-3}$ & $6.50 \times 10^{-8}$ & $\leq 7$ \\
\hline 3.0 & 55.0 & 42.0 & $-58.5 \pm 0.5^{*}$ & $5.00 \times 10^{-8}-1.00 \times 10^{-3}$ & $4.00 \times 10^{-8}$ & $\leq 5$ \\
\hline 5.0 & 55.0 & 40.0 & $-57.8 \pm 0.5$ & $6.50 \times 10^{-8}-6.31 \times 10^{-3}$ & $5.00 \times 10^{-8}$ & $\leq 6$ \\
\hline
\end{tabular}

Mixed ion-exchangers (Nf-ST+Nf-SM)

\begin{tabular}{|c|c|c|c|c|c|c|c|}
\hline \multicolumn{8}{|c|}{ Nf-ST + Nf-SM } \\
\hline \multirow{7}{*}{$\begin{array}{l}3.0 \\
2.5 \\
2.0 \\
1.5 \\
1.0 \\
0.5 \\
0.0\end{array}$} & & G & B & $\mathbf{S}$ & C.R. (M) & LOD (M) & $R(s)$ \\
\hline & & 55.0 & 42.0 & $-60.5 \pm 0.5^{\star}$ & $1.25 \times 10-8-5.00 \times 10-2$ & $1.00 \times 10-8$ & $\leq 5$ \\
\hline & $\begin{array}{l}0.5 \\
1.0\end{array}$ & 55.0 & 42.0 & $-58.5 \pm 0.5$ & $2.50 \times 10-8-1.00 \times 10-3$ & $1.25 \times 10-8$ & $\leq 6$ \\
\hline & \multirow{2}{*}{$\begin{array}{l}1.5 \\
2.0\end{array}$} & 55.0 & 42.0 & $-56.0 \pm 1.0$ & $6.31 \times 10-8-1.00 \times 10-3$ & $5.00 \times 10-8$ & $\leq 7$ \\
\hline & & 55.0 & 42.0 & $-55.0 \pm 1.0$ & $2.50 \times 10-8-1.00 \times 10-3$ & $2.00 \times 10-8$ & $\leq 6$ \\
\hline & \multirow{2}{*}{$\begin{array}{l}2.5 \\
3.0\end{array}$} & 55.0 & 42.0 & $-56.6 \pm 1.0$ & $3.50 \times 10-8-5.00 \times 10-3$ & $2.50 \times 10-8$ & $\leq 7$ \\
\hline & & 55.0 & 42.0 & $-57.8 \pm 0.5$ & $6.50 \times 10-8-6.31 \times 10-3$ & $5.00 \times 10-8$ & $\leq 6$ \\
\hline
\end{tabular}

* The selected sensor

CP: Carbon Paste

C.R.: Concentration Range (M), LOD: Limit of Detection (M), R(s): Response Time (s)

Table 1: Effect of binders on the CP sensor modified by Nf-ST ion exchangers at $25.0 \pm 0.1^{\circ} \mathrm{C}$.

\begin{tabular}{|c|c|c|c|}
\hline Parameters Sensors & Sensor $1 \mathrm{Nf}-\mathrm{ST}$ & Sensor 2 Nf-SM & Sensor $3 \mathrm{Nf}(\mathrm{ST}+\mathrm{SM})$ \\
\hline Composition & $3.0 \%(I . P)$ & $3.0 \%(I . P)$ & $2.5 \%(\mathrm{ST})(\mathrm{I} . \mathrm{P})+$ \\
\hline (W/W\%) & $+55.0 \% \mathrm{G}+42.0 \% \mathrm{P}$ & $+55.0 \% \mathrm{G}+42.0 \% \mathrm{P}$ & $0.5 \%(\mathrm{SM})(\mathrm{I} . \mathrm{P})+55.0 \% \mathrm{G}+42.0 \% \mathrm{P}$ \\
\hline Slope (mV/decade) & $-59.0 \pm 0.5$ & $-58.5 \pm 0.5$ & $-60.5 \pm 0.5$ \\
\hline Correlation coefficient $(r)$ & 0.996 & 0.999 & 0.998 \\
\hline LOD (M) & $1.25 \times 10^{-8}$ & $4.00 \times 10^{-8}$ & $1.00 \times 10^{-8}$ \\
\hline Linear range $(\mathrm{M})$ & $2.50 \times 10^{-8}-1.00 \times 10^{-3}$ & $5.00 \times 10^{-8}-1.00 \times 10^{-3}$ & $1.25 \times 10^{-8}-5.00 \times 10^{-2}$ \\
\hline Working $\mathrm{pH}$ range & $2.0-6.0$ & $2.0-6.0$ & $2.0-6.0$ \\
\hline Response time (s) & $\leq 5 \mathrm{~s}$ & $\leq 5 \mathrm{~s}$ & $\leq 5 \mathrm{~s}$ \\
\hline Recovery $(\%) \pm$ S.D* & $99.12 \pm 0.5$ & $98.55 \pm 0.5$ & $99.25 \pm 0.5$ \\
\hline Robustness & $99.65 \pm 0.5$ & $99.37 \pm 0.5$ & $99.87 \pm 0.5$ \\
\hline Ruggedness & $99.75 \pm 0.5$ & $99.45 \pm 0.5$ & $99.75 \pm 0.5$ \\
\hline
\end{tabular}

* Five replicates

Table 2: Response characteristics of the Ns-ion exchangers at $95 \%$ confidence intervals, average of five replicates at $25.0 \pm 0.1^{\circ} \mathrm{C}$. 
$\mathrm{ST}+0.5 \% \mathrm{Nf}-\mathrm{SM})$, is the best, where the sensor improves, its slope increases from $-59.0 \pm 0.5,-58.5 \pm 0.5$ for Nf-ST, Nf-SM respectively to $-60.5 \pm 0.5 \mathrm{mV} /$ decade and the linear range increases slightly from $2.50 \times 10^{-8}-1.00 \times 10^{-3}, 5.00 \times 10^{-8}-1.00 \times 10^{-3}$ to $1.25 \times 10^{-8}-5.00 \times 10^{-2} \mathrm{M}$ and the detection limit reaches to $0.1 \mathrm{nM}$ as shown in Table 2 .

\section{Reproducibility of the Sensor}

The examination of the repeatability for the potential reading of the Nf-ST/CMCP sensor was taken by the subsequent measurements in $1.0 \times 10^{-3} \mathrm{M} \mathrm{Nf}-(\mathrm{COOH})_{2}$, solution then followed by measuring the first set of solution at $1.0 \times 10^{-4} \mathrm{M} \mathrm{Nf}-(\mathrm{COOH})_{2}$. The standard deviation values for each sensor are given in Table 3 by measuring emf for five replicate measurements. The obtained values indicate the excellent

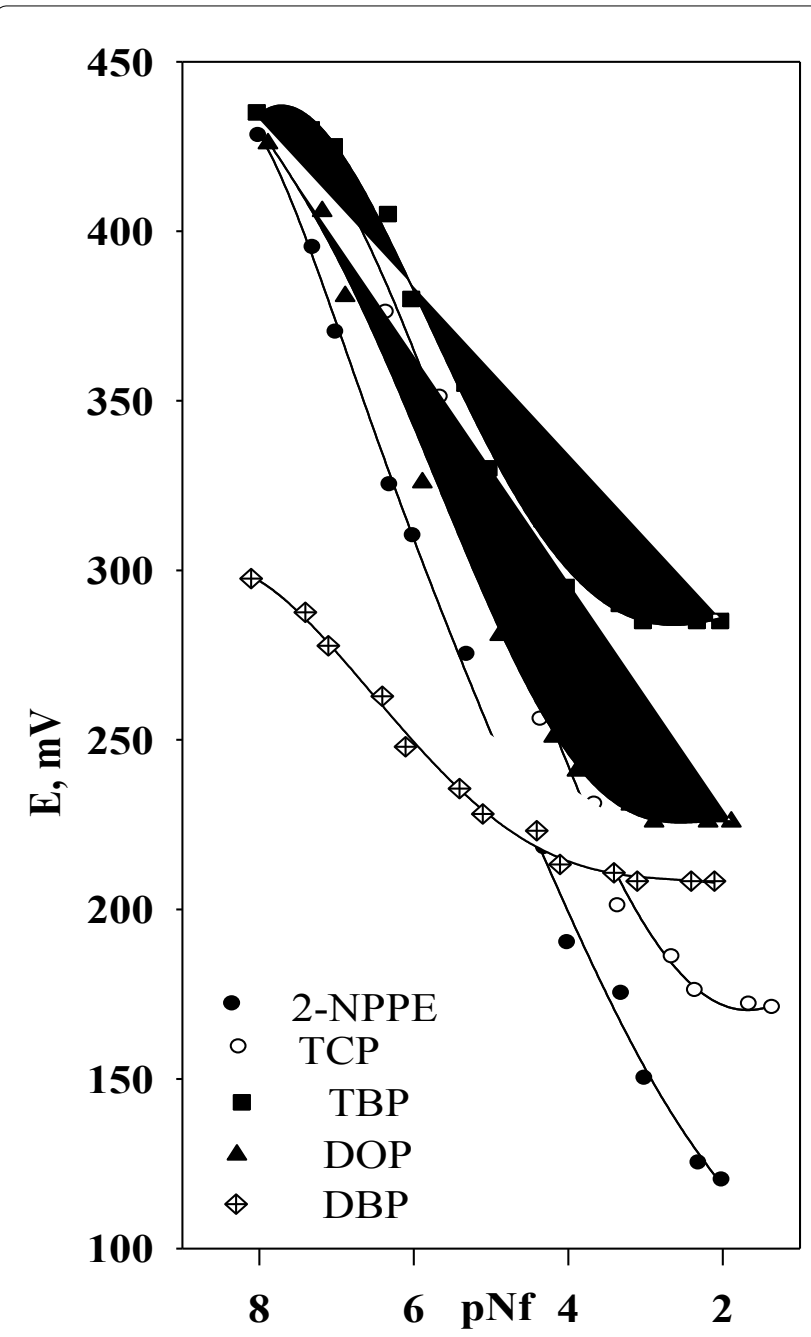

Figure 2: Effect of different binders on NF-CMCPS.

\begin{tabular}{|c|c|c|}
\hline Sensors & \multicolumn{2}{|c|}{ Standard deviation S.D } \\
\hline Nf- Sensors & $1.0 \times 10^{-4 T}$ & $1.0 \times 10^{-3}$ \\
\hline (1) Nf-ST & & \\
\hline (2) Nf-SM & 0.49 & 0.36 \\
\hline (3) Nf (ST+SM) & 0.81 & 0.66 \\
\hline
\end{tabular}

Table 3: The standard deviation values of measuring emf for five replicate measurements obtained for each sensor.

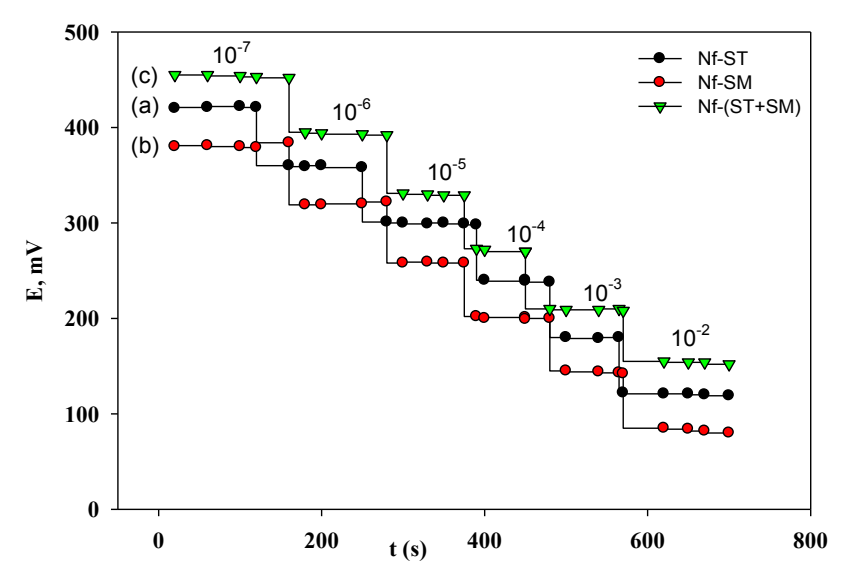

Figure 3: Potential - tine plot for response of the (a) Nf-ST, (b) Nf- SM and (c) $\mathrm{Nf}-(\mathrm{ST}+\mathrm{SM}) / \mathrm{CMCPs}$.

repeatability of the potential response of the sensors. The slope of the calibration graph obtained by the sensors was found to decrease slightly after several times of use, which may be attributed to surface contaminations.

\section{Dynamic response time}

The response time of the sensor is defined as the time between addition of the analyte to the sample solution and the time when a limiting potential has been reached. The dynamic response time [26] was obtained for the sensor by recording the time required to achieve a steady-state potential (within $\pm 1 \mathrm{mV}$ ) after subsequence immersions of the sensor in a series of drug solutions, each having a 10-fold increase in concentration from $1.0 \times 10^{-7}$ to $1.0 \times 10^{-2} \mathrm{M}$. The practical response time was examined by following $\mathrm{Nf}-(\mathrm{COOH})_{2}$ concentration by up to 10 -fold. The sensor reached steady potential within $5-7 \mathrm{sec}$. This is most probably due to the fast exchange kinetics of association-dissociation of naftidrofuryl ion with the ionophores at the solution-paste interface. The potential-time plot for the response of the sensor Nf-CMCPs is shown in Figure 3.

\section{Effect of $\mathbf{p H}$}

In analytical determinations with CMCP sensors, studies were carried out to reach the optimum experimental conditions. The potential of the $\mathrm{pH}$ profile is one parameter that obtained in the studying Nf-CMCPs and the responses of the sensors are almost constant over the $\mathrm{pH}$ range 2.0-6.0. In this range the sensor can be safely used for the determination of the drug. Therefore, there is no need to adjust the $\mathrm{pH}$ or use buffer solution, as the drug solution is in the allowable range of the $\mathrm{pH}$ and the $\mathrm{pH}$ range from 2.0 to 6.0 was assumed to be the working $\mathrm{pH}$ range of the sensors. It can be seen from Figure 4 that at $\mathrm{pH}$ values lower than the $2.0 \mathrm{pH}$ ranges, the potential readings slightly different which can be related to interference of hydronium ion while at $\mathrm{pH}$ values higher than $\mathrm{pH} 6$, the potential readings decrease gradually due to the formation of free base of the drug and decrease of the protonated species in the test solutions.

\section{Effect of temperature}

The investigation of the thermal stability of CMCPs is of prime importance in characterization of their behavior. In case if the thermal coefficient is high, more than $1 \mathrm{mV} /{ }^{\circ} \mathrm{C}$, then it is important that 

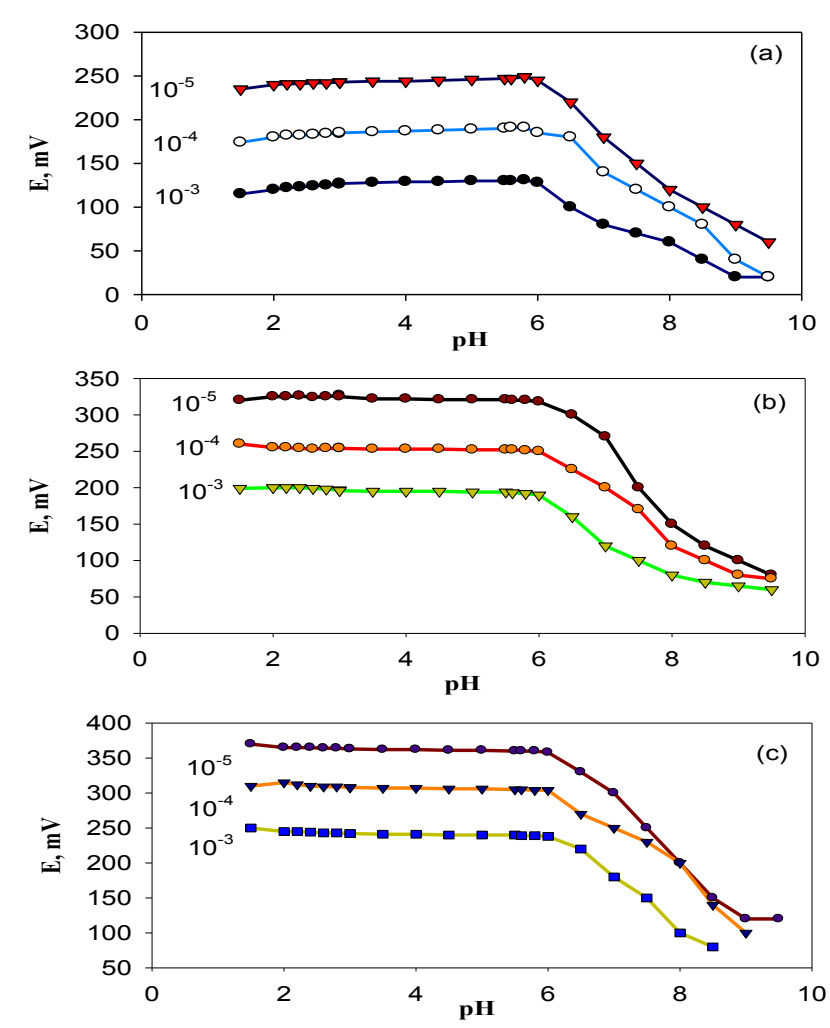

Figure 4: Effect of $\mathrm{pH}$ of the test solution of (a) Nf-SM, (b) Nf-ST, and (c) $\mathrm{Nf}-(\mathrm{ST}+\mathrm{SM}) / \mathrm{CMCPS}$.

\begin{tabular}{|c|c|c|c|}
\hline Sensors & Temperature $\left.\mathbf{~}^{\circ} \mathbf{C}\right)$ & Slope $(\mathbf{m V} /$ decade) & Linear range $(\mathbf{M})$ \\
\hline Sensor 1 & 25 & $-59.0 \pm 0.5$ & $2.50 \times 10^{-8}-1.00 \times 10^{-3}$ \\
\hline & 30 & $-60.0 \pm 0.5$ & $5.00 \times 10^{-7}-7.20 \times 10^{-3}$ \\
\hline & 35 & $-61.0 \pm 0.5$ & $1.00 \times 10^{-6}-3.50 \times 10^{-3}$ \\
\hline & 40 & $-59.0 \pm 0.5$ & $1.25 \times 10^{-5}-2.00 \times 10^{-3}$ \\
\hline & 50 & $-57.0 \pm 0.5$ & $4.00 \times 10^{-5}-1.50 \times 10^{-3}$ \\
\hline Sensor 2 & 25 & $-58.5 \pm 0.5$ & $5.00 \times 10^{-8}-1.00 \times 10^{-3}$ \\
\hline & 30 & $-59.5 \pm 0.5$ & $8.90 \times 10^{-7}-1.60 \times 10^{-3}$ \\
\hline & 35 & $-60.5 \pm 0.5$ & $2.50 \times 10^{-6}-5.00 \times 10^{-3}$ \\
\hline & 40 & $-58.5 \pm 0.5$ & $1.00 \times 10^{-5}-2.00 \times 10^{-3}$ \\
\hline & 50 & $-56.5 \pm 0.5$ & $5.00 \times 10^{-5}-1.90 \times 10^{-3}$ \\
\hline Sensor 3 & 25 & $-60.5 \pm 0.5$ & $1.25 \times 10^{-8}-5.00 \times 10^{-2}$ \\
\hline & 30 & $-61.5 \pm 0.5$ & $5.00 \times 10^{-7}-5.00 \times 10^{-3}$ \\
\hline & 35 & $-62.5 \pm 0.5$ & $2.25 \times 10^{-6}-4.00 \times 10^{-3}$ \\
\hline & 40 & $-60.5 \pm 0.5$ & $7.50 \times 10^{-6}-3.00 \times 10^{-3}$ \\
\hline & 50 & $-58.5 \pm 0.5$ & $1.00 \times 10^{-5}-1.60 \times 10^{-3}$ \\
\hline
\end{tabular}

Table 4: Performance characteristics of Nf-CMCPs at different test solution temperatures.

temperature be controlled as variation in this parameter can lead to significant measurement errors as shown in Table 4.

\section{Sensors selectivity}

In analytical applications, the selectivity for the analyte must be as high as possible, i.e. the selectivity for foreign substances must be very small, so that the sensor exhibits a Nernstian dependence on the primary ion over a wide concentration range. The response of the sensors towards different substances and ionic species such as inorganic/organic cations, amino acids, sugars that may be present in the pharmaceutical preparations was checked both by SSM and or
MPM conditions and the values of selectivity coefficients were used to evaluate of their interference. The inorganic cations do not interfere due to their mobility and permeability is difference as compared to nafronyl cation. For amino acids and sugars the high selectivity is related to the difference in polarity and lipophilic nature of their molecules relative to nafronyl cation as shown in Table 5.

\section{Analytical applications}

Standard addition method: The analytical applications involve determination of the drug in its bulk powder, pharmaceutical dosage form, and human fluids plasma/urine by the standard addition method [24], which is frequently the most, applied one in using CMCPs. The method was proved successful for the determination of nafronyl ions. The data reflect the high accuracy and precision of the investigated sensors for determination of nafronyl ion and its statistical data treatments in comparison with official methods [27,28].

Potentiometric titration: The potentiometric titration technique usually offers the advantage of high accuracy and precision. A further advantage is that the potential break at the titration end-point must be well defined. The titration process was carried in pure solution and/ or pharmaceutical dosage form containing from 2.37-47.36 mg Nf$(\mathrm{COOH})_{2}$. As shown in Figure 5 and Table 6 with its statistical data treatments in comparison with official methods $[27,28]$.

Robustness and ruggedness: The examination of the robustness method was checked by the replacement of aqueous solution with acetate buffer $\mathrm{pH} 4 \pm 0.5$ for the Nf-CMCPSs. All results are in a good agreement with those obtained from standard drug solution as shown in Table 1. In addition, the reproducibility or the ruggedness was examined by using another model type of $\mathrm{pH}$-meter (Jenway, 3510) for each sensor (1,2 and 3$)$. Table 7

\begin{tabular}{|c|c|c|c|c|c|c|}
\hline \multirow[b]{2}{*}{ Interferent } & \multicolumn{2}{|c|}{ Sensor 1} & \multicolumn{2}{|c|}{ Sensor 2} & \multicolumn{2}{|c|}{ Sensor 3} \\
\hline & SSM & MPM & SSM & MPM & SSM & MPM \\
\hline $\mathrm{Na}^{+}$ & 3.43 & 3.71 & 3.22 & 3.65 & 3.55 & 3.83 \\
\hline $\mathrm{NH}_{4}^{+}$ & 3.51 & 3.39 & 3.65 & 3.44 & 3.88 & 3.62 \\
\hline $\mathrm{K}^{+}$ & 3.50 & 3.53 & 3.43 & 3.43 & 3.60 & 3.65 \\
\hline $\mathrm{Cu}^{2+}$ & 3.90 & 3.83 & 3.87 & 3.79 & 3.88 & 4.05 \\
\hline $\mathrm{Zn}^{2+}$ & 3.82 & 3.67 & 3.76 & 3.84 & 3.80 & 4.08 \\
\hline $\mathrm{Co}^{2+}$ & 3.89 & 3.93 & 3.54 & 3.59 & 3.95 & 4.13 \\
\hline $\mathrm{Fe}^{2+}$ & 2.27 & 2.38 & 2.11 & 2.30 & 2.66 & 2.81 \\
\hline $\mathrm{Fe}^{3+}$ & 3.81 & 3.76 & 3.47 & 3.55 & 3.88 & 3.85 \\
\hline $\mathrm{Ni}^{2+}$ & 3.67 & 3.65 & 3.33 & 3.49 & 3.84 & 3.72 \\
\hline $\mathrm{Mn}^{2+}$ & 3.60 & 3.53 & 3.47 & 3.51 & 3.73 & 3.65 \\
\hline $\mathrm{Mg}^{2+}$ & 3.75 & 3.85 & 3.24 & 3.33 & 3.81 & 4.02 \\
\hline $\mathrm{Cr}^{3+}$ & 3.93 & 4.02 & 3.95 & 3.89 & 4.08 & 4.23 \\
\hline $\mathrm{Ba}^{2+}$ & 4.05 & 4.23 & 3.77 & 3.94 & 4.13 & 4.27 \\
\hline Glucose & -- & 3.61 & -- & 3.44 & -- & 3.71 \\
\hline Maltose & -- & 3.73 & -- & 3.39 & -- & 3.85 \\
\hline Lactose & -- & 3.61 & -- & 3.46 & -- & 3.69 \\
\hline Urea & -- & 3.54 & -- & 3.25 & -- & 4.01 \\
\hline $\begin{array}{l}\text { Ascorbic } \\
\text { acid }\end{array}$ & -- & 3.58 & -- & 3.42 & -- & 4.03 \\
\hline Asparagine & -- & 3.83 & -- & 3.53 & -- & 3.93 \\
\hline L-Lysine & -- & 3.94 & -- & 3.56 & -- & 4.11 \\
\hline L-cystine & -- & 3.96 & -- & 3.73 & -- & 4.05 \\
\hline L-Glycine & -- & 3.97 & -- & 3.67 & -- & 4.08 \\
\hline L-Theronine & -- & 3.89 & -- & 3.55 & -- & 4.15 \\
\hline
\end{tabular}

Table 5: Selectivity coefficient values for - log $K^{\text {pot }}$ Nf/CMCPS. 


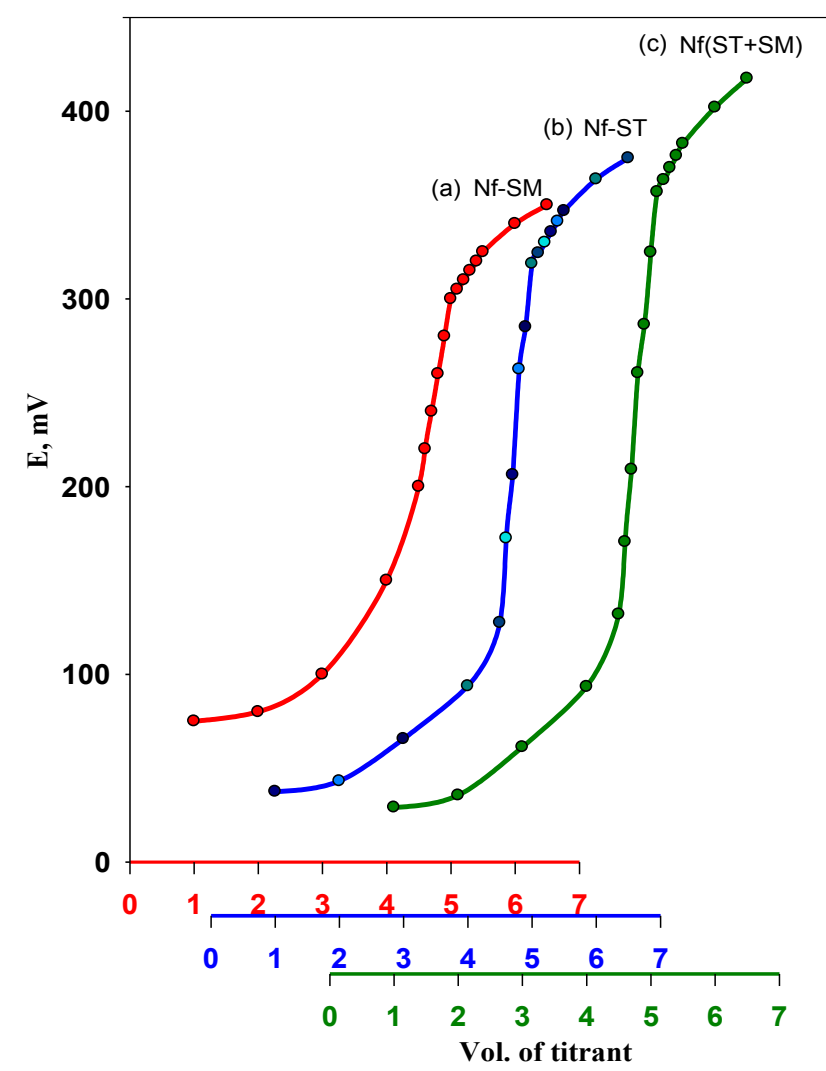

Figure 5: Potentiometric titration of $23.68 \mathrm{mg} \mathrm{Nf}(\mathrm{COOH})$, with $2.5 \times 10^{-4} \mathrm{M}$ STA As titrant using sensors (a) Nf-SM, (b) Nf-ST and (c) NF(ST+SM).

\section{Content uniformity of Praxilene tablets}

The content uniformity assay for Nf-CMCPS method described good accuracy, reproducible results and precision for the quality control tests so the sensors can be working for the quantification determination of nafronyl ions and the percentage of the recovery of $\mathrm{Nf}-(\mathrm{COOH})_{2}$ is almost acceptance quantitatively.

\section{Validation of the proposed method}

Linearity and detection limit (LOD): The value of LOD was indicating that the proposed method is sensitive for detection of very small concentrations of Nf-CMCPSs reach to $0.1 \mathrm{nM}$, the correlation coefficient (r) and other statistical parameters were listed in Table 1.

Accuracy: The investigation of accuracy for the proposed NfCMCPS method was examined by determination of nafronyl ions in its pharmaceutical preparations without interfering from the co formulated adjuvant as indicated and the recovery value showed excellent procedure of the investigated sensors.

Precision: The precision of the Nf-CMCPS method was tested by repeating the proposed CMCPS method for analysis of the investigated nafronyl ions in intra-day (within the day) and inter-day (consecutive days) to five replicates measured as percentage relative standard deviation (\% RDS). The percentage RSD values are less than $2 \%$, indicating acceptable and good precision.

Determination of the solubility products of the ionexchangers

It is noteworthy to mention that the solubility of an ion-exchanger is one of the main factors controlling the sensitivity of the ion-selective sensor, which incorporate this ion-exchanger as electroactive material. This is confirmed by the values of solubilites whereas the solubilities have the lowest value the detection limits also have as given in Table

\begin{tabular}{|c|c|c|c|c|c|c|c|}
\hline \multirow{2}{*}{\begin{tabular}{|l|} 
Pure solutions \\
Taken (mg)
\end{tabular}} & \multirow[t]{2}{*}{ Official(1) method } & \multicolumn{2}{|c|}{ Sensor 1} & \multicolumn{2}{|c|}{ Sensor 2} & \multicolumn{2}{|c|}{ Sensor 3} \\
\hline & & Recovery (\%) & R.S.D.\% & Recovery (\%) & R.S.D.\% & Recovery (\%) & R.S.D.\% \\
\hline 4.74 & & 99.21 & 1.11 & 98.84 & 0.53 & 99.18 & 0.27 \\
\hline 7.11 & & 99.53 & 0.85 & 98.75 & 0.38 & 99.25 & 0.33 \\
\hline 14.20 & & 99.00 & 0.97 & 98.55 & 0.47 & 99.78 & 0.78 \\
\hline$X \pm$ S.E. & $98.5 \pm 0.5$ & \multicolumn{2}{|c|}{$99.25 \pm 0.05$} & \multicolumn{2}{|c|}{$98.71 \pm 0.12$} & \multicolumn{2}{|c|}{$99.40 \pm 0.09$} \\
\hline F value & & \multicolumn{2}{|c|}{1.85} & \multicolumn{2}{|c|}{2.05} & \multicolumn{2}{|c|}{1.45} \\
\hline$t$ value & & \multicolumn{2}{|c|}{2.74} & \multicolumn{2}{|c|}{2.93} & \multicolumn{2}{|c|}{1.89} \\
\hline \multicolumn{8}{|l|}{ Praxilene $(200 \mathrm{mg})$} \\
\hline 4.74 & & 99.85 & 0.76 & 98.23 & 0.87 & 100.58 & 0.54 \\
\hline 7.11 & & 100.54 & 0.25 & 98.66 & 1.05 & 101.89 & 0.93 \\
\hline 14.20 & & 101.25 & 0.35 & 98.47 & 1.25 & 101.25 & 0.36 \\
\hline$X \pm$ S.E. & $101.7 \pm 0.5$ & \multicolumn{2}{|c|}{$100.55 \pm 0.05$} & \multicolumn{2}{|c|}{$98.45 \pm 0.52$} & \multicolumn{2}{|c|}{$101.24 \pm 0.14$} \\
\hline F value & & \multicolumn{2}{|c|}{2.51} & \multicolumn{2}{|c|}{1.81} & \multicolumn{2}{|c|}{1.37} \\
\hline t value & & \multicolumn{2}{|c|}{1.39} & \multicolumn{2}{|c|}{1.55} & \multicolumn{2}{|c|}{0.76} \\
\hline \multicolumn{8}{|l|}{ Spiked Plasma } \\
\hline$X \pm$ S.E. & & \multicolumn{2}{|c|}{$101.95 \pm 0.50$} & \multicolumn{2}{|c|}{$101.70 \pm 0.35$} & \multicolumn{2}{|c|}{$101.20 \pm 0.15$} \\
\hline F value & & \multicolumn{2}{|c|}{0.84} & \multicolumn{2}{|c|}{1.23} & \multicolumn{2}{|c|}{0.44} \\
\hline t value & & \multicolumn{2}{|c|}{0.73} & \multicolumn{2}{|c|}{1.09} & \multicolumn{2}{|c|}{0.39} \\
\hline Spiked Urine & & & & & & & \\
\hline$X \pm$ S.E. & & 101.5 & .25 & 101.6 & & 101. & \\
\hline F value & & & & & & & \\
\hline t value & & & & & & & \\
\hline
\end{tabular}

$\mathrm{X} \pm$ S.E: Recovery \pm standard error F- tabulated is 6.39 at $95.0 \%$ confidence limit, t-tabulated at $99.0 \%$ confidence limit and 6 degrees of freedom (1) British Pharmacopoeia (Non-aqueous titration with $0.1 \mathrm{M}$ perchloric acid)

Table 6: Determination of Nf-CMCPs applying the standard addition method in bulk powder, Praxilene (200 mg) and spiked human plasma/urine and its statistical data treatments in comparison with official methods. 
Citation: Khorshid AF (2014) Chemically Modified Carbon Sensors Mixed or Single for the Determination of Cardiovascular Drug Nafronyl Oxalate in Bulk, Praxilene and Human Fluids. J Biosens Bioelectron 5: 153. doi: 10.4172/2155-6210.1000153

Page 8 of 10

\begin{tabular}{|c|c|c|c|c|c|c|c|}
\hline \multirow{3}{*}{$\begin{array}{l}\text { Pure solutions } \\
\text { Taken (mg) } \\
\text { STA as titrant }\end{array}$} & \multirow[t]{3}{*}{ Official(1) method } & \multicolumn{2}{|c|}{ Sensor 1} & \multicolumn{2}{|c|}{ Sensor 2} & \multicolumn{2}{|c|}{ Sensor 3} \\
\hline & & \multirow{2}{*}{ Recovery (\%) } & \multirow{2}{*}{ R.S.D.\% } & \multirow{2}{*}{ Recovery (\%) } & \multirow{2}{*}{ R.S.D.\% } & \multirow{2}{*}{ Recovery (\%) } & \multirow{2}{*}{ R.S.D. \% } \\
\hline & & & & & & & \\
\hline 14.20 & & 99.23 & 0.88 & 98.77 & 0.49 & 99.66 & 0.37 \\
\hline 23.68 & & 99.75 & 0.79 & 98.95 & 0.58 & 99.25 & 0.68 \\
\hline 33.15 & & 99.45 & 0.84 & 98.56 & 0.18 & 99.73 & 0.84 \\
\hline 47.36 & & 99.83 & 1.25 & 99.10 & 0.52 & 99.84 & 1.52 \\
\hline$X \pm S . E$. & $98.50 \pm 0.50$ & \multicolumn{2}{|c|}{$99.57 \pm 0.35$} & \multicolumn{2}{|c|}{$98.85 \pm 1.11$} & \multicolumn{2}{|c|}{$99.62 \pm 0.58$} \\
\hline F value & & \multicolumn{2}{|c|}{2.59} & \multicolumn{2}{|c|}{2.33} & \multicolumn{2}{|c|}{2.08} \\
\hline t value & & \multicolumn{2}{|c|}{2.35} & \multicolumn{2}{|c|}{2.12} & \multicolumn{2}{|c|}{2.65} \\
\hline \multicolumn{8}{|l|}{ SMA as titrant } \\
\hline 14.20 & & 98.44 & 1.35 & 98.05 & 1.22 & 98.60 & 1.56 \\
\hline 23.68 & & 98.38 & 1.68 & 98.36 & 1.73 & 98.94 & 1.24 \\
\hline 33.15 & & 98.47 & 1.62 & 98.05 & 1.65 & 98.66 & 1.33 \\
\hline 47.36 & & 98.92 & 1.45 & 98.00 & 1.85 & 98.25 & 1.40 \\
\hline$X \pm S . E$ & $98.50 \pm 0.50$ & \multicolumn{2}{|c|}{$98.55 \pm 0.52$} & \multicolumn{2}{|c|}{$98.10 \pm 0.23$} & \multicolumn{2}{|c|}{$98.61 \pm 0.14$} \\
\hline F value & & \multicolumn{2}{|c|}{2.33} & \multicolumn{2}{|c|}{2.14} & \multicolumn{2}{|c|}{1.58} \\
\hline$t$ value & & \multicolumn{2}{|c|}{2.27} & \multicolumn{2}{|c|}{2.56} & & \\
\hline Praxilene $(200 \mathrm{mg}) \mathrm{s}$ & as titrant & & & & & & \\
\hline 14.20 & & 100.75 & 0.31 & 101.15 & 0.23 & 100.15 & 0.41 \\
\hline 23.68 & & 100.25 & 0.06 & 101.31 & 0.47 & 100.43 & 0.32 \\
\hline 33.15 & & 100.63 & 0.22 & 101.25 & 0.55 & 100.63 & 0.04 \\
\hline$X \pm S . E$. & $101.70 \pm 0.50$ & 100.5 & .22 & 101.2 & & 100. & \\
\hline F value & & & & & & & \\
\hline$t$ value & & & & & & & \\
\hline Praxilene $(200 \mathrm{mg}) \mathrm{s}$ & as titrant & & & & & & \\
\hline 14.20 & & 101.44 & 0.81 & 101.65 & 0.39 & 101.13 & 0.48 \\
\hline 23.68 & & 101.68 & 0.43 & 101.88 & 0.63 & 101.40 & 0.35 \\
\hline 33.15 & & 101.45 & 0.11 & 101.94 & 0.45 & 101.67 & 1.04 \\
\hline$X \pm S . E$. & $101.70 \pm 0.50$ & 101.5 & .15 & 101.8 & & 101 & \\
\hline F value & & & & & & & \\
\hline t value & & & & & & & \\
\hline
\end{tabular}

$\mathrm{X} \pm$ S.E: Recovery \pm standard error F-tabulated is 6.39 at $95.0 \%$ confidence limit, t-tabulated at $99.0 \%$ confidence limit and 6 degrees of freedom

Table 7: Determination of Nf-CMCPs applying the potentiometric titration method in bulk powder and Praxilene (200 mg) with its statistical data treatments in comparison with official methods.

\begin{tabular}{|l|c|c|c|c|}
\hline & & Ksp & & \\
\hline Ion-associates & $\mathrm{S}$ & Potentiometric method (P) & conductimetric method (C) & Limit of detection (LOD) M \\
\hline $\mathrm{Nf}_{4} \mathrm{ST}$ & $7.45 \times 10^{-7}$ & $8.35 \times 10^{-27}$ & $8.56 \times 10^{-27}$ & $1.25 \times 10^{-8}$ \\
\hline $\mathrm{Nf}_{4} \mathrm{SM}$ & $6.23 \times 10^{-7}$ & $5.44 \times 10^{-27}$ & $4.61 \times 10^{-27}$ & $4.00 \times 10^{-8}$ \\
\hline
\end{tabular}

S: Solubility $(\mathrm{mol} / \mathrm{l}) \quad \mathrm{K}$ : Equilibrium constant

Table 8: Solubility product constants of ion-associates

8. This is in agreement with what was stated by Pungor and Toth [29]. The reciprocal of the solubility product is approximately equal to the equilibrium constant $(\mathrm{K})$ of the precipitation reaction employed in such titration.

$$
\mathrm{A}^{\mathrm{n}-}+\mathrm{n} \mathrm{D}^{+} \leftrightarrow \mathrm{D}_{\mathrm{n}} \mathrm{A} \quad \mathrm{K}=1 / \mathrm{KSP}
$$

$\mathrm{A}^{\mathrm{n}-}$ is the counter anion and $\mathrm{D}^{+}$is the drug cation, number of experiments $(\mathrm{N})=4$.

\section{Potentiometric monitoring of Plavix tablet dissolution}

The changes in the electrochemical potential of the dissolution medium caused by the dissolving drug can be detecting by the sensor monitors to the dissolution of the tablet. These changes are converted into the concentration in \% of dissolved drug via dedicated ("Potential measured in $\mathrm{mV}$, to Concentration"). The results are compared to subsequent sample analysis using UV. It shows that nafronyl releases immediately after capsule was ruptured. Taking into account that the

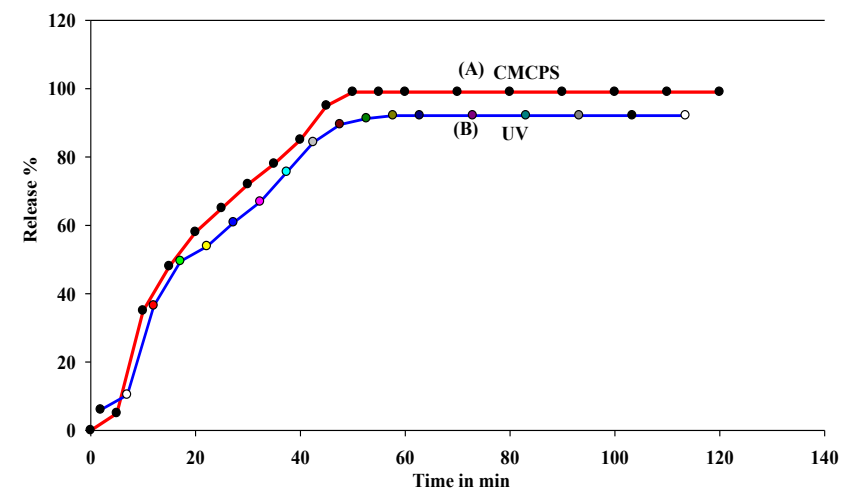

Figure 6: Dissolution profiles of $200 \mathrm{mg}$ naftidrofuryl tablets obtained by (A) potentiometric: Mized sensor NF-CMCPS, and (B) spectrophotometric measurements at $283 \mathrm{~nm}$. 
Citation: Khorshid AF (2014) Chemically Modified Carbon Sensors Mixed or Single for the Determination of Cardiovascular Drug Nafronyl Oxalate in Bulk, Praxilene and Human Fluids. J Biosens Bioelectron 5: 153. doi: 10.4172/2155-6210.1000153

Page 9 of 10

\begin{tabular}{|c|c|c|c|c|c|c|}
\hline & Ref. 9 & Ref. 10 & Ref. 11 & C.S & C.S & C.S \\
\hline & & & & Sensor $1 \mathrm{Nf}-\mathrm{ST}$ & Sensor 2 Nf-SM & Sensor $3 \mathrm{Nf}(\mathrm{ST}+\mathrm{SM})$ \\
\hline Parameter & NFT-dipicrylamine & NFL-CD/PVC-COOH & $\begin{array}{l}\text { NFT-sulfocal- } \\
\text { ix-8-arene }\end{array}$ & $\begin{array}{c}3.0 \%(\mathrm{II}) \\
+55.0 \% \mathrm{G}+42.0 \% \mathrm{P}\end{array}$ & $\begin{array}{c}3.0 \%(\mathrm{II}) \\
+55.0 \% \mathrm{G}+42.0 \% \mathrm{P}\end{array}$ & $\begin{array}{c}2.5 \% \text { (ST) (I.P)+ } \\
0.5 \% \text { (SM) (I.P)+55.0\% G+42.0\% P }\end{array}$ \\
\hline Slope (mV/decade) & $-54-56$ & -50.5 & -54.1 & $-59.0 \pm 0.5$ & $-58.5 \pm 0.5$ & $-60.5 \pm 0.5$ \\
\hline Correlation coefficient $(r)$ & --- & 0.9974 & 0.9993 & 0.996 & 0.999 & 0.998 \\
\hline Linear range (M) & $10^{-5}-10^{-2}$ & $10^{-5}-10^{-3}$ & $1 \times 10^{-5}-1 \times 10^{-2}$ & $2.50 \times 10^{-8}-1.00 \times 10^{-3}$ & $5.00 \times 10^{-8}-1.00 \times 10^{-3}$ & $1.25 \times 10^{-8}-5.00 \times 10^{-2}$ \\
\hline LOD (M) & --- & ---- & $5.6 \times 10^{-6}$ & $1.25 \times 10^{-8}$ & $4.00 \times 10^{-8}$ & $1.00 \times 10^{-8}$ \\
\hline Working $\mathrm{pH}$ range & $2-5$ & $2.50-4.50$ & $2-5$ & $2.0-6.0$ & $2.0-6.0$ & $2.0-6.0$ \\
\hline Response time (s) & --- & $20-30$ & 9 & $\leq 5 \mathrm{~s}$ & $\leq 5 \mathrm{~s}$ & $\leq 5 \mathrm{~s}$ \\
\hline Life span/days & --- & $6-8 w$ & $14 \mathrm{~d}$ & Fresh surface & & \\
\hline Accuracy (\%) & --- & $100.13 \pm 1.61$ & $99.97 \pm 0.89$ & $99.12 \pm 0.5$ & $98.55 \pm 0.5$ & $99.25 \pm 0.5$ \\
\hline Standard deviation & $\leq 2.0 \%$ & 1.612 & & less than $2.0 \%$ & & \\
\hline Robustness & --- & --- & --- & $99.65 \pm 0.5$ & $99.37 \pm 0.5$ & $99.87 \pm 0.5$ \\
\hline Ruggedness & --- & --- & --- & $99.75 \pm 0.5$ & $99.45 \pm 0.5$ & $99.75 \pm 0.5$ \\
\hline
\end{tabular}

$r^{2}$ : Correlation coefficient $\quad R \%$ : Mean recovery $\% \quad$ C.S: Current Study

Table 9: Comparison between the published and the current methods for determination of Nf-ISS.

releasing was achieved in three stages; the first during 15 min nearly $50 \%$ was released, the second more than $74 \%$ drug was released within $30 \mathrm{~min}$ and complete dissolution in the third stage within $45 \mathrm{~min}$ according to USP [19].

For the UV spectrophotometric assay, fixed volumes of the dissolution medium were withdrawn, diluted with $0.01 \mathrm{M} \mathrm{HCl}$, measured at $\lambda \max 283 \mathrm{~nm}$ and compared with a calibration graph. Figure 6 shows the dissolution profiles of nafronyl tablet using both measurement techniques. The results obtained by spectrophotometric and potentiometry are almost identical but the use of the potentiometric method sensor has the advantage of more sensitive due to overcome the matrix effect.

\section{Comparison of the nafronyl selective sensors}

The earlier research described Nafronyl ion-selective membrane electrodes with either the nafronyl-dipicrylamine ion-pair complex in 1,2-dichloroethane or the nafronyl-dinonylnaphthalenesulphonic acid ion-pair complex in a PVC matrix as electroactive materials were used Ref. 9 . Membrane selective electrodes to determine Naftidrofuryl Oxalate (NFL) in presence of its alkaline degradate (I). The membrane selective electrodes include construction of water insoluble ionassociation complexes. These are NFL-tetraphenyl borate (NFL-TPB), NFL-reinikate (NFL-R). These complexes are used as electroactive materials, in poly-vinyl chloride (PVC) matrix membrane sensors, for the determination of NFL Ref. 10 . Sensors for the quantitative determination of NFT in pure form, pharmaceutical formulations, in the presence of its degradation products, in plasma and CSF. The use of sulphonated calix-8-arene as ionophores increased the membrane sensitivity Ref. 11 . But no method was found for the quantitative determination of NFT by chemical modified carbon paste sensor (CMCPs) as the present work.

For comparison, the performance characteristics of the choice sensor and the reported ISE method are showed in Table 9. It is noteworthy that the proposed sensor CMCPS is comparable with most of the reported sensors with regard to working concentration range, response time and low detection limit. The comparisons indicate that the present sensor is high selective than the previous methods in applications.

\section{Conclusion}

The preparation and investigation of the performance characteristics of CMCPS for the determination of cardiovascular drug naftidrofuryl ion. The proposed potentiometric methods based on the construction of different selective sensors with ion exchangers in analytical characteristics for the determination of $\mathrm{Nf}-(\mathrm{COOH})_{2}$ in its pure solutions, pharmaceutical preparation and human fluids. The excellent recoveries and low relative standard deviations obtained reflect the high accuracy and precision of the proposed method. In addition, the method is easy to operate, high sensitivity, simple, fast static response; reasonable selectivity; long term stability and applicability over a wide concentration range with minimal sample pretreatment and inexpensive making it an excellent tool for the routine determination of $\mathrm{Nf}$ in quality control laboratories. The sensor developed is superior as compared with the naftidrofuryl selective sensor described in the literature [9-11].

\section{Acknowledgement}

I gratefully acknowledge the support of National Organization for drug control and research (NODCAR) in Giza-Egypt, by the chemicals and dissolution equipment also acknowledge the supporting of Central Research Lab at Nahda University with the other equipments at the practical work.

\section{References}

1. British Pharmacopoeia: Volumes I and II (2009) Her Majesty's Stationary Office. London, UK.

2. Sweetman SC (2007) Martindale-The Complete Drug Reference.The Pharmaceutical Press, London.

3. Brodie RR, Chasseaud LF, Taylor T, Hunter JO, Ciclitira PJ (1979) Determination of naftidrofuryl in the plasma of humans by high-performance liquid chromatography. J Chromatogr 164: 534-540.

4. Garrett ER, Barbhaiya R (1981) Prediction of stability in pharmaceutical preparations. XVIII: Application of high-pressure liquid chromatographic assays to study of nafronyl stability and bioanalysis. J Pharm. Sci. 70: 39-45.

5. Beyer KH, Hildebrand M (1982) Naftidrofuryl (Dusodril) Possible uses of gas chromatography and high pressure liquid chromatography for analysis. Dtsch. Apoth. Ztg. 122: 1709-1712.

6. Walmsley LM, Wilkinson PA, Brodie RR, Chasseaud LF (1985) Determination of naftidrofuryl in human plasma by high-performance liquid chromatography with fluorescence detection. J Chromatogr 338: 433-437.

7. Waaler P J, Mueller BW (1992) Solid-phase extraction of naftidofuryl from human plasma for high performance liquid chromatography analysis. Int. J. Pharm. 87: 223-227.

8. Cawood A, Marshall IW (1975) Estimation of naftidrofuryl in sodium chloride solution. J. Hosp. Pharm. 33: 149-151.

9. Ionescu MS, Badea V, Baiulescu GE, Coayofreae VV (1986) Nafronyl ion- 
Citation: Khorshid AF (2014) Chemically Modified Carbon Sensors Mixed or Single for the Determination of Cardiovascular Drug Nafronyl Oxalate in Bulk, Praxilene and Human Fluids. J Biosens Bioelectron 5: 153. doi: 10.4172/2155-6210.1000153

selective membrane electrodes and their use in pharmaceutical analysis. Talanta 33: 101-103.

10. Samah S Abbas, Hala E Zaazaa, Mohamed R El-Ghobashy, Yasmin M Fayez, Soheir A Fattah, (2012) Application of Membrane-Selective Sensors for the Determination of Naftidrofuryl Oxalate in the Presence of Its Alkaline Degradant in Tablets and Plasma. Port. Electrochim. Acta 30.

11. El-Sayed MA (2013) The use of calixarene as ionophores in potentiometric ionselective sensors of naftidrofuryl oxalate using microsized membrane sensors for kinetic study of naftidrofuryl (NF) degradation. Eur. J. of Chemistry 4:124131

12. Munoz de la Pena A, Espinosa Mansilla A, Murillo Pulgarin JA, Alanon Molina A, Fernandez Lopez P (1998) Determination of nafronyl in pharmaceutical preparations by means of stopped-flow micellar-stabilized room temperature phosphorescence. Analyst 123: 2285-2290.

13. Murillo Pulgarin JA, Alanon Molina A, Fernandez Lopez P (1999) Phosphorimetric determination of nafronyl in pharmaceutical preparations. Analytica Chimica Acta 382: 77-85.

14. Cruces-Blanco C, Seguro Carretero A, Fernandez Sanchez JF, Fernandez Gutierrez A (2000) Facile and selective determination of the cerebral vasodilator nafronyl in a commercial formulation by heavy atom induced room temperature phosphorimetry. J Pharm Biomed Anal 23: 845-50.

15. Segura-Carretero A, Cruces-Blanco C, Canabate-Diaz B, Fernandez-Sanchez JF, Fernandez Gutierrez A, et al. (2000) Heavy-atom induced room-temperature phosphorescence: a straightforward methodology for the determination of organic compounds in solution. Analytica Chimica Acta 417: 19-30.

16. Fernandez-Sanchez JF, Segura-Carretero A, Cruces-Blanco C, FernandezGutierrez A (2002) Room-temperature luminescence optosensings based on immobilized active principles actives: Application to nafronyl and naproxen determination in pharmaceutical preparations and biological fluids. Analytica Chimica Acta 462: 217-24.

17. Švancara I, Vytras K, Kalcher K, Walcarius A (2009) Carbon Paste Sensors in Facts, Numbers, and Notes: A Review on the Occasion of the 50-Years Jubilee of Carbon Paste in Electrochemistry and Electroanalysis. Electroanalysis 21 $7-28$
18. Švancara I, Walcarius A, Kalcher K, Vytras K (2009) Carbon paste sensors in the new millennium. Central European Journal of Chemistry 7: 598-656.

19. United States Pharmacopeia (2009) National Formulary USP 32-NF 27 Convention, Inc.: Rockville, MD.

20. Deng G, Ashley AJ, Brown WE, Eaton JW, Hauck WW, et al. (2008) The USP Performance Verification Test, Part I: USP Lot P Prednisone Tablets: quality attributes and experimental variables contributing to dissolution variance. Pharm Res 25: 1100-1109.

21. Khorshid AF, Issa YM (2014) Modified carbon paste sensor for the potentiometric determination of neostigmine bromide in pharmaceutical formulations, human plasma and urine. Biosens Bioelectron 51: 143-149.

22. Umezawa Y, Buhlmann P, Umezawa K, Tohda K, Amemiya S, et al. (2000) Potentiometric selectivity coefficients of ion-selective sensors. Part I. Inorganic cations (technical report). Pure Appl Chem 72: 1851-2082.

23. Umezawa Y, Umezawa K, Sato H (1995) Selectivity coefficients for ionselective sensors: recommended methods for reporting $K A, B$ pot values (technical report). Pure Appl Chem 67: 507-11.

24. Guilbault G, Drust RA, Frant MS, Freiser H, Hansen, et al (1976) Recommendations for nomenclature of ion-selective sensors. Pure Appl Chem 48: 127-29.

25. Antropov LI (1972) Theoretical Electrochemistry. Mir Moscow.

26. Linder E, Umezawa Y (2008) Performance evaluation criteria for preparation and measurement of macro- and micro fabricated ion-selective sensors. Pure Appl Chem. 80: 85-104.

27. Skoog DA, Holler FJ, Neiman TA (1997) Principles of Instrumental Analysis Harcourt Brace College Publishers, London.

28. Miller JC, Miller JN (1994) Statistics for Analytical Chemistry. Ellis Horwood Chichester, England.

29. Pungor E, Toth E (1970) Analyst 95: 625. 